\title{
Transferência de nervos (neurotizações) no tratamento das lesões traumáticas do plexo braquial
} Nerve transfer (neurotizations) in the treatment of brachial plexus injuries

Edie Benedito Caetano ${ }^{1}$, Luiz Angelo Vieira ${ }^{1}$, Antonio Marcos de Andrade ${ }^{1}$, Cristina Schmitt Cavalheiro ${ }^{1}$, Mauro Razuk Filho ${ }^{1}$

\begin{abstract}
RESUMO
As lesões por avulsão das raízes do plexo braquial usualmente são causadas por acidentes de automóveis e motocicletas. Suas consequências são devastadoras e representam um desafio aos cirurgiões que tratam de tais pacientes. É de fundamental importância o intervalo entre a lesão e o tratamento definitivo. O tratamento das lesões por avulsão do plexo braquial envolve a utilização de neurólises, sutura direta das extremidades do nervo, enxertos de nervos e procedimentos de neurotizações. Vários nervos têm sido utilizados como doadores nas neurotizações. Geralmente, existem dois tipos de doadores: extraplexual (nervos intercostal, acessório e frênico, ramos motores do plexo cervical e raiz C7 contralateral) e intraplexual (coto proximal das raízes ou ramos motores colaterais de nervos do plexo braquial que foram preservados). A neurotização intraplexual representa a forma clássica das transferências nervosas.

Palavras-chave: transferência de nervo; plexo braquial; ferimentos e lesões; resultado do tratamento.
\end{abstract}

\begin{abstract}
Brachial plexus avulsion injuries are usually caused by car and motorcycle accidents. Their consequences are devastating and represent a challenge to the surgeons who assist these patients. Positive results of this procedure depend on the interval between the injury and the definitive treatment. The treatment of brachial plexus avulsion injuries invariably involves the use of neurolysis, direct nerve repair, nerve grafts, and neurotization procedures. Several nerves have been used as donors in neurotizations. In general, there are two types of donor: extraplexal (intercostal, spinal accessory, and phrenic nerves, motor branches of the cervical plexus, and contralateral C7 root) and intraplexal (proximal spinal nerve stumps or collateral motor branches of the preserved brachial plexus). In fact, the intraplexal neurotization represents the classical form of nerve transfers.
\end{abstract}

Keywords: nerve transfer; brachial plexus; wounds and injuries; treatment outcome.

\section{ATUALIZAÇÃO}

As lesões nervosas do plexo braquial atingem preferencialmente pessoas jovens, com maior frequência do sexo masculino, como consequência de acidentes de motocicletas. Em geral, as lesões nervosas, sobretudo as recentes, são reparadas por meio de neurorrafia (união por meio de cirurgia dos cotos nervosos proximal e distal), conforme observado nas Figuras 1A e 1B. Esse procedimento deve ser realizado, de preferência, antes de seis meses após a lesão. As neurólises consistem na dissecção dos nervos, com o objetivo de liberar tais nervos dos tecidos fibróticos adjacentes. ${ }^{1}$

Nas situações em que os cotos não podem ser aproximados, é possível empregar enxertos nervosos. Os segmentos nervosos danificados são removidos e substituídos por enxertos nervosos, utilizando nervos de menor importância funcional como doadores, por exemplo, o nervo sural da perna., ${ }^{2,3}$

Caso o coto proximal de um nervo não esteja presente, como quando ocorrem avulsões das raízes do plexo braquial da medula espinhal, a alternativa é a transferência de outro nervo (neurotização interneural). Essa técnica consiste no uso de um nervo com função não fundamental, para substituir outro com função fundamental. A neurotização interneural pode ser intraplexual, entre os próprios nervos que se originam do plexo braquial, ou extraplexual, quando os nervos doadores não pertencem ao plexo braquial. Entre os doadores, têm-se os nervos para a porção longa ou lateral do músculo tríceps

'Pontifícia Universidade Católica de São Paulo (PUC-SP), Faculdade de Ciências Médicas e da Saúde - Sorocaba (SP), Brasil. Contato: ediecaetano@uol.com.br

Recebido em 19/01/2016. Aceito para publicação em 31/05/2016. 
braquial, os nervos intercostais, o nervo acessório (XI nervo craniano), o nervo frênico, a raiz C7 contralateral ou o nervo hipoglosso (XII nervo craniano). Quando o coto distal não está presente, tem-se como alternativa o implante do nervo diretamente no músculo (neurotização intramuscular). ${ }^{4-6}$

Quando acontece perda dos movimentos do ombro e flexão do cotovelo, trata-se de uma lesão das raízes C5 e C6; se há perda dos movimentos de extensão do punho e dos dedos, a raiz C7 também está afetada. Quando não existe movimento tampouco dos flexores dos dedos e punho, constitui paralisia completa, ou seja, as raízes C8 e T1 também foram afetadas. Nas lesões do tipo superior, em que ocorre a avulsão (arrancamento) das raízes C5 e C6 do plexo braquial, os movimentos do ombro e a flexão do cotovelo ficam comprometidos. Nessa situação, são utilizadas múltiplas transferências nervosas. Portanto, o nervo acessório, XI nervo craniano, é transferido ao supraescapular. O nervo da porção longa do músculo tríceps braquial é transferido para o axilar antes da emergência do ramo motor para o músculo redondo menor. Tal procedimento provoca apenas uma discreta diminuição da força de extensão do cotovelo. Esses dois procedimentos têm como finalidades estabilizar e restaurar os movimentos de abdução e rotação lateral (rotação externa) do ombro (Figura 2).

A flexão do cotovelo pode ser restaurada mediante dois fascículos do nervo ulnar, que originalmente se direcionam ao músculo flexor ulnar do carpo (identificados por estimulação elétrica) e, nesse procedimento, são conectados ao ramo motor do bíceps (ramo do nervo musculocutâneo). Assim, não se acarreta prejuízo importante para fletir o punho, no entanto parestesias provisórias ocorrem com frequência. ${ }^{7}$ Outro procedimento que pode ser empregado para restaurar a flexão do cotovelo é a utilização de dois fascículos do nervo mediano, os quais originalmente se dirigem aos músculos flexores do carpo (flexor radial do carpo e palmar longo) e, nesse caso, são conectados ao ramo motor do músculo braquial, que também é do nervo musculocutâneo. Essas duas técnicas podem ser associadas (Figura 3).
A proximidade entre os nervos doador e receptor tem possibilitado a recuperação da flexão do cotovelo antes de seis meses. A transferência dos nervos intercostais (normalmente utilizados do segundo ao sétimo), que foi muito usada há alguns anos para restaurar a flexão do cotovelo, não tem sido muito empregada recentemente, embora ainda seja a escolha de alguns cirurgiões. Alguns autores consideram que a neurotização dos nervos intercostais é de difícil reeducação. Em geral, dois ou três nervos intercostais são expostos na linha axilar média e prolongados com enxerto de nervo sural, que tem a mesma espessura que os intercostais, para alcançar ou o nervo musculocutâneo ou o radial. O enxerto de nervo sural (7 a $10 \mathrm{~cm}$ de comprimento) é necessário nesse procedimento para

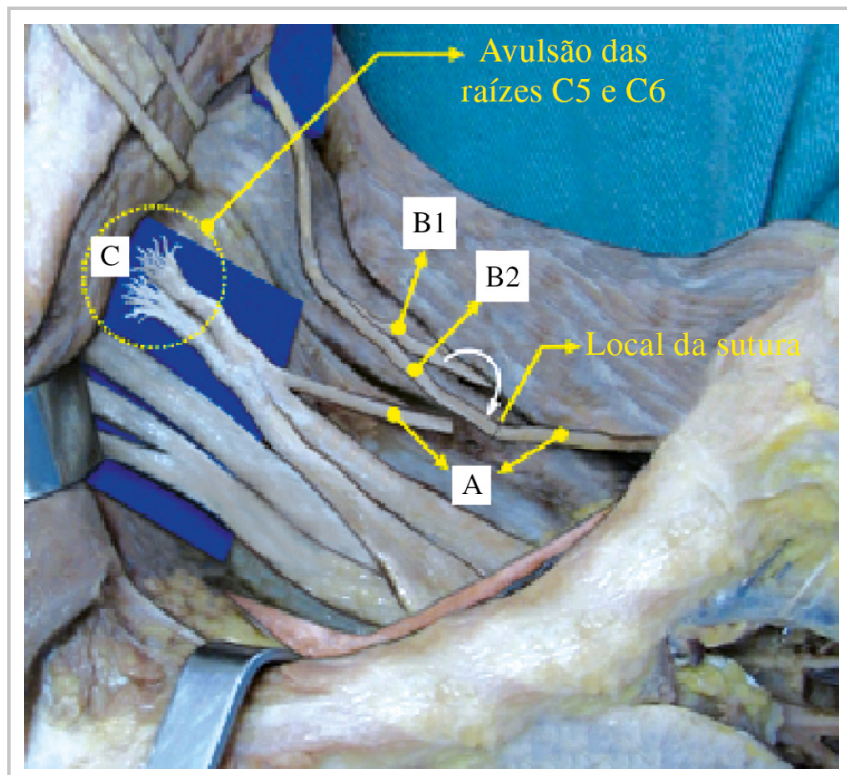

A: Uso do nervo acessório; B1: antes da transposição; B2: como doador depois da transposição. Observar a avulsão das raízes C5 e C6.

Figura 2. Procedimento de neurotização do nervo supraescapular.
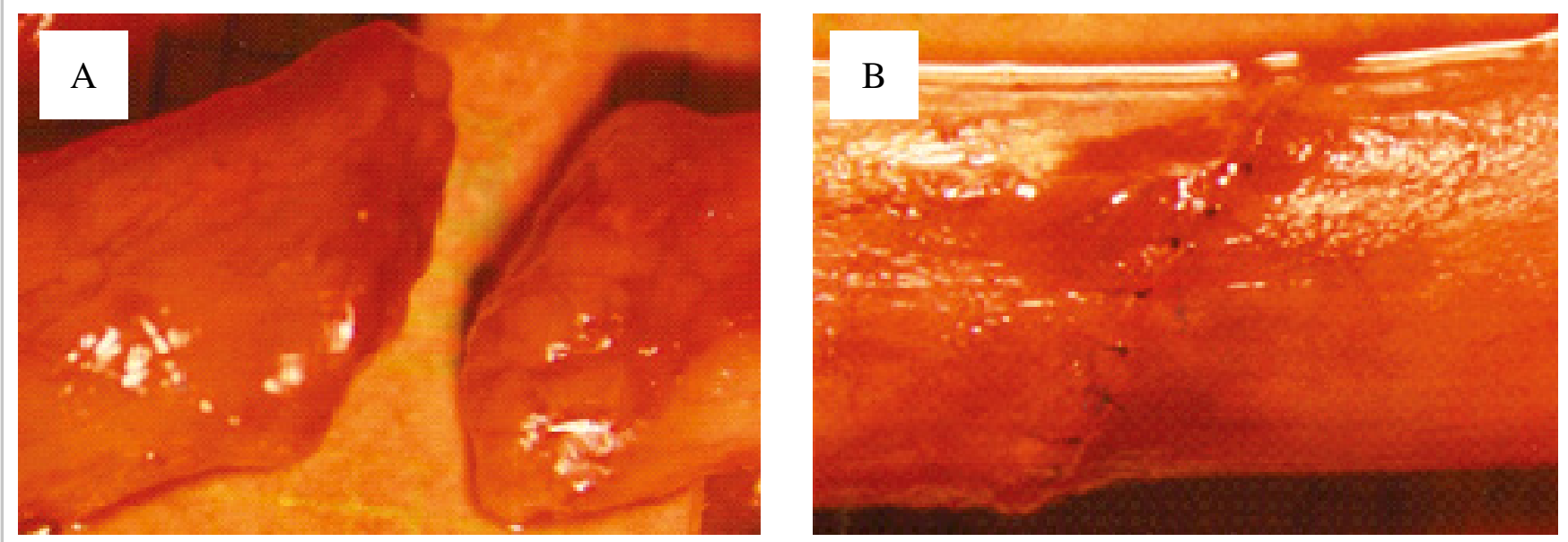

A: Secção traumática recente de um nervo periférico (caso intraoperatório); B: reparação da lesão com sutura microcirúrgica.

Figuras 1 (A e B). Neurorrafia. 


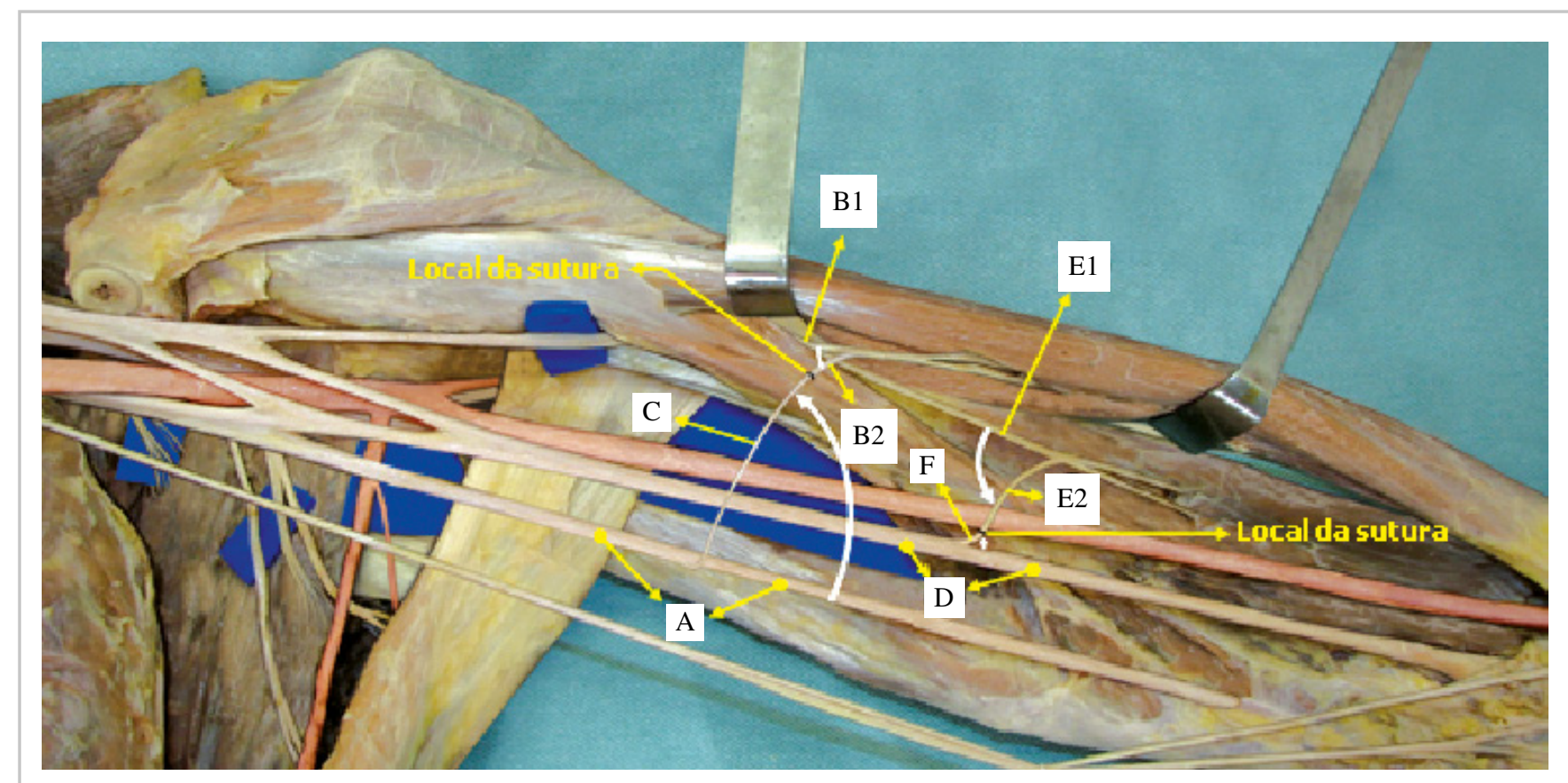

A: Ramo motor do bíceps; B1: antes da transferência; B2: depois da transferência. Dois fascículos do nervo ulnar que se direcionam ao flexor ulnar do carpo (identificados por estimulação elétrica); C: nervo mediano; D: ramo motor do músculo braquial; E1 e E2: antes e depois da transferência nervosa; F: dois fascículos do nervo mediano que se direcionam ao flexor radial do carpo e palmar longo.

Figura 3. Nervo ulnar.

evitar o excesso de tensão caso os nervos intercostais sejam conectados diretamente com os do plexo braquial. ${ }^{1,7}$

Nas lesões por avulsão de todas as raízes do plexo braquial, algum tipo de preensão precisa ser restaurado. Como a preensão pelo uso da mão é muito difícil de ser obtida, a cirurgia está voltada à reconstrução de uma pinça toracobraquial (para segurar objetos entre o braço e o tórax). Para isso, devem-se restaurar a adução do braço pela reinervação dos músculos peitorais, alguma abdução pela reinervação do nervo supraescapular e, se possível, alguma flexão do cotovelo pela reinervação do musculocutâneo. Essas reinervações podem ser conseguidas com o uso de raízes remanescentes do plexo braquial ou por transferências dos nervos: acessório, motor do plexo cervical para o músculo levantador da escápula, intercostais, frênico, a raiz $\mathrm{C} 7$ do plexo braquial do membro contralateral e até o nervo hipoglosso. Todos esses procedimentos, quando indicados, devem ser realizados em seis meses após o acidente. Depois de tal período, a reinervação dos músculos paralisados torna-se cada vez mais difícil. ${ }^{4} \mathrm{~A}$ restauração de alguma sensibilidade na face volar do polegar e indicador pode ser obtida pela transferência dos ramos sensitivos supraclaviculares do plexo cervical para a raiz lateral do nervo mediano.

Outras possibilidades para transferência de nervos têm sido descritas. A raiz $\mathrm{C} 7$ contralateral (com a qual os autores deste trabalho não têm experiência) tem sido empregada recentemente. Esta contém um grande número de fibras nervosas e, de modo surpreendente, o déficit no membro doador não tem sido significante. Bertelli e Ghizoni, ${ }^{3}$ as maiores autoridades no tratamento de lesões do plexo braquial em nosso meio, têm utilizado apenas alguns fascículos da raiz $\mathrm{C} 7$ contralateral para reinervar os nervos supraescapular ou musculocutâneo. Além disso, esse sistema também tem sido o escolhido por apresentar maior superposição territorial, com menor risco de alterações permanentes. A transferência da raiz C7 para o nervo mediano tem proporcionado o retorno de alguma sensibilidade nos dedos, porém a recuperação dos músculos do antebraço e da mão é muito pobre.

Outra possibilidade nas lesões altas do plexo braquial (raízes C5 e C6) é a transferência do nervo peitoral medial (que tem origem no fascículo medial) para o musculocutâneo ou axilar. Essa transferência, por conter um pequeno número de fibras nervosas, proporciona melhores resultados, principalmente quando associada a outras.

O músculo platisma é uma lâmina muscular no tecido subcutâneo do pescoço. Existem enormes variações anatômicas em relação às dimensões desse músculo. O platisma tensiona a pele do pescoço, formando pregas. A inervação do platisma provém do ramo cervical do nervo facial. A parte inferior do platisma, no entanto, pode eventualmente ser inervada por um ramo do plexo cervical. Nesse caso, esse ramo pode também ser utilizado como doador nas neurotizações. ${ }^{3}$

\section{REFERÊNCIAS}

1. Lanaras TI, Schaller HE, Sinis N. Brachial plexus lesions: 10 years of experience in a center for microsurgery in Germany. Microsurgery. 2009;29(2):87-94.

2. Wolfe SW, Johnsen PH, Lee SK, Feinberg JH. Longnerve grafts and nerve transfers demonstrate comparable outcomes for axillary nerve injuries. J Hand Surg Am. 2014;39(7):1351-7. 
3. Bertelli JA, Ghizoni MF. Reconstruction of complete palsies of the adult brachial plexus by root grafting using long grafts and nerve transfers to target nerves. J Hand Surg Am. 2010;35(10):1640-6.

4. Chuang DC, Hernon C. Minimum 4-year follow-up on contralateral C7 nerve transfers for brachial plexus injuries. J Hand Surg Am. 2012;37(2):270-6.

5. Pet MA, Ray WZ, Yee A, Mackinnon SE. Nerve transfer to the triceps after brachial plexus injury: report of four cases. J Hand Surg Am. 2011;36(3):398-405.
6. Zheng MX, Xu WD, Qiu YQ, Xu JG, Gu YD. Phrenic nerve transfer for elbow flexion and intercostal nerve transfer for elbow extension. J Hand Surg Am. 2010;35(8):1304-9.

7. Ferraresi S, Garozzo D, Basso E, Maistrello L, Lucchin F, Di Pasquale P. The medial cord to musculocutaneous (MCMc) nerve transfer: a new method to reanimate elbow flexion after C5-C6-C7-(C8) avulsive injuries of the brachial plexus - technique and results. Neurosurg Rev. 2014;37(2):321-9. 